\title{
Early- and late-migrating cranial neural crest cell populations have equivalent developmental potential in vivo
}

\author{
Clare V. H. Baker ${ }^{1,2, \star}$, Marianne Bronner-Fraser ${ }^{1}$, Nicole M. Le Douarin² and Marie-Aimée Teillet ${ }^{2}$ \\ ${ }^{1}$ Division of Biology, Beckman Institute 139-74, California Institute of Technology, Pasadena, California 91125, USA \\ 2Institut d'Embryologie cellulaire et moléculaire du CNRS et du Collège de France, 49bis avenue de la Belle Gabrielle, 94736 \\ Nogent-sur-Marne Cedex, France \\ *Author for correspondence currently at address 1
}

\section{SUMMARY}

We present the first in vivo study of the long-term fate and potential of early-migrating and late-migrating mesencephalic neural crest cell populations, by performing isochronic and heterochronic quail-to-chick grafts. Both early- and late-migrating populations form melanocytes, neurons, glia, cartilage and bone in isochronic, isotopic chimeras, showing that neither population is lineagerestricted. The early-migrating population distributes both dorsally and ventrally during normal development, while the late-migrating population is confined dorsally and forms much less cartilage and bone. When the latemigrating population is substituted heterochronically for the early-migrating population, it contributes extensively to ventral derivatives such as jaw cartilage and bone. Conversely, when the early-migrating population is substituted heterochronically for the late-migrating population, it no longer contributes to the jaw skeleton and only forms dorsal derivatives. When the late-migrating population is grafted into a late-stage host whose neural crest had previously been ablated, it migrates ventrally into the jaws. Thus, the dorsal fate restriction of the late-migrating mesencephalic neural crest cell population in normal development is due to the presence of earlier-migrating neural crest cells, rather than to any change in the environment or to any intrinsic difference in migratory ability or potential between early- and late-migrating cell populations. These results highlight the plasticity of the neural crest and show that its fate is determined primarily by the environment.

Key words: neural crest, chick, quail, cell migration, cell fate

\section{INTRODUCTION}

During early vertebrate embryogenesis, neural crest cells are generated from the ectoderm at the border between prospective neural plate and prospective epidermis (reviewed by Selleck and Bronner-Fraser, 1996). They subsequently leave the dorsal midline in a rostrocaudal sequence and migrate throughout the embryo to give rise to many and varied derivatives. These derivatives include melanocytes, most of the neurons and glia of the peripheral nervous system, and cranial skeletal components such as cartilage, bone and dermis (Le Douarin, 1982). Lineagetracing of single neural crest cells in vivo, and clonal analysis in vitro, have demonstrated the existence of multipotent neural crest cells at both premigratory and migratory stages in avian and mammalian embryos (Sieber-Blum and Cohen, 1980; Baroffio et al., 1988, 1991; Bronner-Fraser and Fraser, 1988, 1989; Fraser and Bronner-Fraser, 1991; Stemple and Anderson, 1992; Serbedzija et al., 1994). Hence the neural crest provides a model system for the generation of diverse cell types from pluripotent precursor cells.

The time at which a neural crest cell leaves the neural tube influences the migration pathway it follows and the derivatives it forms. In the zebrafish, early-migrating neural crest cells form neurons (Raible and Eisen, 1994; Schilling and Kimmel,
1994), while in the head, late-migrating cells form cartilage (Schilling and Kimmel, 1994). In avian embryos, earlymigrating trunk neural crest cells follow a ventromedial pathway through the rostral somite to form components of the peripheral nervous system, while cells that migrate a day later follow a dorsolateral pathway between the ectoderm and somites, and exclusively form melanocytes (Weston, 1963; Tosney, 1978; Serbedzija et al., 1989; Erickson et al., 1992; Kitamura et al., 1992). Recently, a much later wave of neural crest cell emigration has been described to occur through the dorsal root, giving rise to dorsal root ganglion neurons as well as melanocytes (Sharma et al., 1995).

Changes in neural crest cell fate with time could be due to temporal changes in neural crest cell potential, and/or temporal changes in the environment through which they migrate. In avian and mammalian embryos, progressively later injections of dye into the neural tube at all axial levels result in the progressive loss of dye-labelled cells from more ventral derivatives (Serbedzija et al. 1989, 1991, 1992). This suggests that late-migrating neural crest cells in these embryos form dorsal derivatives but not ventral derivatives. In the head, for example, late-migrating neural crest cells form neurons in cranial ganglia but not cartilage in the branchial arches. Is this simply because late-migrating neural crest cells are restricted to dorsal regions and thus are not exposed 
to the cartilage-promoting signals in the branchial arches (as suggested by Lumsden et al., 1991), or is it due to a difference in potential between early- and late-migrating cells (as suggested by Nichols, 1986)? Early- and late-migrating neural crest cells have also been proposed to differ in melanogenic potential, such that early-migrating cells are unable to form melanocytes (Kitamura et al., 1992). We set out to test these hypotheses by specifically labelling early- or late-migrating cranial neural crest cells using the quail-chick chimera technique, and by performing heterochronic transplants to test the ability of late-migrating neural crest cells to form 'early' derivatives and vice versa. We were also interested in determining whether early-migrating neural crest cells only form ventral derivatives or whether they contribute to all potential target sites; this was not previously known since both early- and late-migrating cells are labelled by early dye injections into the neural tube.

We grafted the recently emigrated neural crest cell population immediately adjacent to the mesencephalon from quail to chick embryos. We show that neither the early-migrating (8somite stage) nor the late-migrating (12-somite stage) avian mesencephalic neural crest cell populations are lineagerestricted, both forming melanocytes, neurons, glia, cartilage and bone during normal development. The early-migrating population contributes to both dorsal and ventral derivatives, while the late-migrating population contributes only to dorsal derivatives and makes much less cartilage and bone. If the latemigrating population is substituted heterochronically for the early-migrating population, it behaves like early-migrating crest, contributing extensively to cartilage and bone in the jaws. Conversely, the early-migrating population forms only dorsal derivatives when substituted heterochronically for latemigrating neural crest. This highlights the importance of the environment in the determination of neural crest cell fate.

\section{MATERIALS AND METHODS}

\section{Microsurgery}

Fertilised quail (Coturnix coturnix japonica) and chick (Gallus gallus domesticus, JA57, ISA, Lyon, France; or White Leghorn) eggs were obtained from commercial sources and incubated at $38^{\circ} \mathrm{C}$ in a humidified atmosphere. Embryos were staged according to the number of somites formed or the number of days of incubation. Neural crest cells were excised according to the method previously described by Smith et al. (1979) and Ziller et al. (1983). Two types of grafts were performed: isochronic and heterochronic.

For grafts of early-migrating neural crest, donor embryos were taken at approximately the 7- to 8-somite stage, when the earliest-migrating mesencephalic neural crest can be seen as a fringe on either side of the neural tube (see Fig. 1A). For isochronic grafts of early-migrating neural crest, host and donor embryos were staged according to the extent of neural crest cell migration, which does not always correspond precisely with particular somite number or head morphology. For grafts of late-migrating neural crest, donor embryos were taken at the 12- to 13-somite stage. A window was cut in the quail/chick shell and a 1:10 mixture of India ink and Tyrode's solution injected into the sub-blastodermic cavity to reveal the embryo. The vitelline membrane in the region of the surgery was removed using either a microscalpel made by sharpening a steel sewing needle on an Arkansas stone, or a pulled glass needle. The strip of ectoderm and underlying migrating neural crest cells on one side of the mesencephalon were excised, trying to minimise contamination with mesodermal/endothelial cells. The width of the graft encompassed approximately 15-25 cells (see Fig. 1D). The posterior limit of the excision was at the level of the mesencephalic- rhombencephalic constriction unless otherwise indicated. Since the diencephalic-mesencephalic boundary is not always visible at this stage, the anterior limit of the graft was less precisely defined, falling approximately two-thirds of the distance between the optic vesicle and the mesencephalic-rhombencephalic constriction (see Fig. 1A).

Some grafts included the region adjacent to the metencephalon; other grafts involved the heterotopic transfer of the mesencephalic ectoderm and neural crest adjacent to the metencephalon (see main text). For the early ablation, late graft experiments (see main text), host embryos were taken at stages ranging from 6 to 9 somites, and the neural folds (and any already-migrating neural crest) unilaterally excised from the mesencephalic+metencephalic region using a pulled glass needle. The hosts were allowed to grow to the 12-somite stage, when late-migrating (12-somite stage) quail neural crest was isotopically grafted either on the ablated side alone, or on both ablated and control sides of the host embryo.

\section{Histological analysis}

70 chimeric embryos were killed at various stages from 1 hour to 13 days after the operation (Table 1), fixed in Carnoy's solution $(60 \%$ ethanol, 30\% chloroform, $10 \%$ acetic acid), embedded in paraffin and sectioned at 5-6 $\mathrm{m}$. Embryos older than 5 days were fixed or embedded under reduced air pressure to ensure adequate penetration and maintenance of structural integrity; some older embryos were sectioned at 10 $\mu \mathrm{m}$. To identify quail cells originating from the graft, sections were stained with the monoclonal quail-specific antibody QCPN (Developmental Hybridoma Bank, University of Iowa; used as undiluted hybridoma supernatant; secondary antibody was goat anti-mouse IgG1). Other antibodies used were HNK-1 to mark neural crest cells (Tucker et al., 1984; used as undiluted hybridoma supernatant; secondary antibody was goat anti-mouse $\operatorname{IgM}$ ), anti-neurofilament (NF) to mark neurons (monoclonal antibody RMO 270.3; Lee et al., 1987; a gift from Dr Virginia Lee; used at 1:300 in phosphate-buffered saline [PBS]; secondary antibody was goat anti-mouse $\mathrm{IgG}$ ) and QH1 to mark quail endothelial cells (Pardanaud et al., 1987; used as undiluted hybridoma supernatant; secondary antibody was goat anti-mouse IgG1). Secondary antibodies were obtained from Southern Biotechnology Associates or Zymed Laboratories. All washes were performed in PBS. For QCPN staining, endogenous peroxidase was blocked by incubating sections for 30 minutes in $0.015 \%$ hydrogen peroxide in PBS; the sections were then washed in PBS, incubated in undiluted hybridoma supernatant at $4{ }^{\circ} \mathrm{C}$ overnight, followed (after washing in PBS) by incubation for 2-3 hours at room temperature in horseradish peroxidase (HRP)-conjugated goat anti-mouse IgG1 at 1:200 in PBS. The colour reaction was performed in $0.05 \mathrm{mg} / \mathrm{ml}$ diaminobenzidene 3-3' tetrahydrochloride (DAB; Sigma), $0.005 \%$ hydrogen peroxide in PBS. Gill's hematoxylin was used as a background nuclear stain. Alcian blue was used to stain cartilage. For double-staining, sections were first incubated with QCPN (following the procedure described above), then, after the $\mathrm{DAB}$ colour reaction, the sections were incubated overnight at $4^{\circ} \mathrm{C}$ with the non-QCPN antibody, followed by 2 hours at room temperature in alkaline phosphatase (AP)conjugated secondary antibody at 1:300 in PBS. The AP colour reaction was performed using AP substrate kit I (red) or IV (blue; both from Vector Laboratories), according to the manufacturer's instructions. Gill's hematoxylin was used as a background nuclear stain. Some QCPN staining was also performed using an AP-conjugated secondary antibody and AP substrate kit IV (Vector Laboratories).

\section{Whole-mount antibody staining}

For whole-mount QCPN staining using alkaline phosphatase, Carnoy's-fixed embryos (see above) were rehydrated into PBS, then treated identically to sections except that the AP-conjugated secondary antibody incubation time was 3-4 hours. For whole-mount QCPN staining using DAB, Carnoy's-fixed embryos were treated similarly to sections (see above) except that the HRP-conjugated secondary antibody incubation time was 3-4 hours, and the colour reaction was performed using $0.5 \mathrm{mg} / \mathrm{ml} \mathrm{DAB}$. 


\section{RESULTS}

The first neural crest cells to migrate in the avian embryo leave the mesencephalon at the 6-somite stage, and move as a sheet of cells beneath the ectoderm (Tosney, 1982). The front of the migrating neural crest is clearly visible under the dissecting microscope as a 'fringe' on either side of the mesencephalon at the 7- to 8-somite stage, i.e. 1-2 hours after neural crest cell emigration has first begun (Fig. 1A). Neural crest cells continue to emigrate from the mesencephalon until about the 10-somite stage, such that the last mesencephalic neural crest cells leave the tube 4-6 hours after the first cells (Tosney, 1982), and are adjacent to the neural tube at about the 12-somite stage.

Fig. 1A shows a quail donor at the 8-somite stage from which the right-hand fringe of migrating mesencephalic neural crest, plus the overlying ectoderm, is being removed. The graft width varies between about 10 and 15 cells (see e.g. Fig. 1C), always includes the leading edge of the migrating neural crest, and in length spans most of the mesencephalon. This strip is grafted into a chick host to replace the corresponding chick fringe (Fig. 1B); the donor and host are matched according to the extent of the neural crest fringes rather than the number of somites, but this is typically at the 7- to 8-somite stage. For grafts of latemigrating neural crest, a similar strip of cells is taken from the area immediately adjacent to the mesencephalon at the 12- to 13-somite stage. Early-migrating cells are then far from the neural tube. Twenty-eight isochronic grafts of early-migrating mesencephalic crest, 14 of late-migrating crest, and 13 heterochronic grafts were analysed after fixation at various stages, from 1 hour to 13 days after the graft (Table 1 ).

\section{The grafts heal quickly and graft-derived neural crest cells migrate normally}

In embryos receiving a graft of early-migrating neural crest sectioned 1-2 hours after the graft and stained with the quailspecific antibody QCPN, the graft ectoderm has healed completely with that of the host, with no mixing of chick and quail ectoderm, and lateral migration of grafted neural crest cells away from the quail ectoderm is well underway (5 embryos; Fig. 1C). Relative to the extent of host neural crest cell migration on the other side of the embryo, the grafted neural crest cells suffer a minor delay in their migration, presumably due to the short time taken for healing of the graft (not shown). Host neural crest cells migrate immediately behind the grafted quail cells (Fig. 1C). Some endothelial cells are carried over with the graft as shown by staining for the quail endothelial cell-specific antibody QH1 (Fig. 1D). Any contamination with underlying mesoderm is minor, and does not in any case affect the interpretation of our results as the derivatives of the mesencephalic neural crest and paraxial mesoderm have been extensively mapped, and they overlap very little (Noden, 1978a,b; Couly et al., 1992, 1993).

By 24 hours after the graft ( 5 embryos), a few quail cells are still associated with the graft ectoderm, while the rest are found along normal neural crest cell migration pathways (Noden, 1975): some are located dorsal to the eye (Fig. 1E), while the majority are found in the maxillary and mandibular arches (Fig. $1 \mathrm{~F})$.

\section{The ectoderm does not migrate ventrally with the neural crest}

The final location of the quail ectoderm after grafts of either early-migrating or late-migrating neural crest was examined by whole-mount QCPN staining of chimeric embryos killed 4 days post-operation (two embryos after early-migrating grafts; three embryos after late-migrating grafts; all embryos were subsequently sectioned for quail neural crest cell analysis). It is clear that in both types of experiment (Fig. $1 \mathrm{G}, \mathrm{H})$, the graftderived ectoderm remains dorsal and does not migrate ventrally with the neural crest into the branchial arches as had been suggested by Noden $(1984,1993)$. Although at the 3-somite stage (well before neural crest cell migration starts), the ectoderm adjacent to the cranial neural fold is fated to form the ectoderm of the branchial arches (Couly and Le Douarin, 1990), our results clearly show that the ectoderm adjacent to the mesencephalon at either the 8- or 12-somite stage does not migrate with the neural crest that moves beneath it.

\section{Early-migrating mesencephalic neural crest cells contribute to dorsal and ventral derivatives during normal development}

The derivatives of the avian mesencephalic neural crest have been analysed by grafting tritiated thymidine-labelled neural folds into unlabelled hosts (Johnston, 1966; Noden, 1975) and

Table 1. Numerical breakdown of the 70 embryos killed at different stages after isochronic and heterochronic grafts of migrating quail cranial neural crest and overlying ectoderm into chick hosts

\begin{tabular}{|c|c|c|c|c|c|c|c|c|}
\hline \multirow[b]{2}{*}{$\begin{array}{l}\text { Age } \\
\text { post-graft }\end{array}$} & \multicolumn{8}{|c|}{ Number of embryos used for each graft } \\
\hline & $8 \mathrm{~s}$ to $8 \mathrm{~s}$ & $12 \mathrm{~s}$ to $12 \mathrm{~s}$ & $8 \mathrm{~s}$ to $12 \mathrm{~s}$ & $12 \mathrm{~s}$ to $8 \mathrm{~s}$ & $\begin{array}{c}8 \mathrm{~s} \text { mes to } \\
8 \mathrm{~s} \text { r } 1,2\end{array}$ & $5 / 6 \mathrm{~s}$ to $8 \mathrm{~s}$ & $\begin{array}{l}\text { Early abl, } \\
\text { late graft }\end{array}$ & Total \\
\hline 1-2 hours & 3 & - & 2 & & & & & 5 \\
\hline 4-8 hours & 3 & - & 1 & 2 & & & & 6 \\
\hline 12-24 hours & 5 & 1 & - & & & & 6 & 12 \\
\hline $1.5-3$ days & 4 & $3 \dagger$ & - & 2 & & & 4 & 13 \\
\hline 4-6 days & $9 *$ & $7 \ddagger$ & 3 & 3 & 2 & $3 \S$ & & 27 \\
\hline $7-13$ days & 4 & $3 \S$ & - & & & & & 7 \\
\hline Total & 28 & 14 & 6 & 7 & 2 & 3 & 10 & 70 \\
\hline
\end{tabular}

All are isotopic grafts at the mesencephalic level unless otherwise indicated. ' $12 \mathrm{~s}$ to $8 \mathrm{~s}$ ' etc. means that the donor had 12 somites while the host had 8 somites at the time of the operation. mes, mesencephalic; r1,2, rhombomeres 1 and 2 (metencephalic); abl, ablation.

*Four of these grafts included the region adjacent to $\mathrm{r} 1,2$.

$\dagger$ One of these grafts included only the region adjacent to $\mathrm{r} 1,2$.

$\$$ Two of these grafts included only the region adjacent to $r 1,2$.

$\S$ One of these grafts included the region adjacent to $\mathrm{r} 1,2$. 
by construction of quail-chick chimeras (Noden, 1978a,b; Narayanan and Narayanan, 1978a,b; Le Lièvre, 1974, 1978; Le Lièvre and Le Douarin, 1975; Couly et al., 1992, 1993). They comprise melanocytes (in the skin and in the choroid layer of the eye); the neurons of the parasympathetic ciliary ganglion and of the sensory trigeminal mesencephalic (Mes V) nucleus; Schwann cells; cartilage, bone and dermis of the jaws, tongue and much of the skull; the corneal endothelium and stromal fibroblasts; and connective components of lacrimal glands, eye muscles, and the telencephalic meninges.

After performing isotopic grafts of the early-migrating (8somite stage) mesencephalic neural crest, we analysed 17 chimeric embryos killed from 2 to 13 days post-graft (dpg; i.e. ranging in age from E3.5 to E14.5; Table 1). We found a quail cell contribution to all the above-listed derivatives except the telencephalic meninges and the Mes V nucleus, as shown in Figs 2 and 3. Quail melanocytes are found both in the skin (Fig. 2A,B) and the choroid layer of the eye (Fig. 2C), while quail neurons are found in the ciliary ganglion (Fig. 2D; see next section). Quail Schwann cells are consistently found along the trigeminal and oculomotor nerves (Fig. 2E) and along nerves in the frontonasal mass (not shown). Quail cells make a substantial contribution to cartilage and bone (Fig. 2F,G) and to other connective tissues such as dermis, glandular connective tissue and the corneal endothelium (not shown) The absence of quail cells in the telencephalic meninges and the MesV nucleus may reflect the fact that our grafts contained neural crest cells that had moved away from the mesencephalon. Cells contributing to the meninges and to the MesV nucleus presumably remain closely associated with the neuroepithelium and thus are not included in our grafts. Narayanan and Narayanan (1978a) demonstrated a neural crest origin for MesV neurons by grafting the neural crest cells that have just left the neural tube, but are still very closely associated with the neuroepithelium, at the 6-somite stage.

Detailed analyses of the neural crest cell contribution to the skull from various brain regions have previously been performed (Le Lièvre, 1974; Noden, 1978a; Couly et al.,

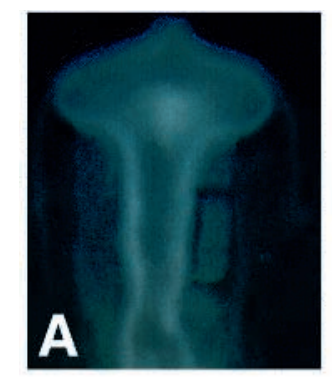

1993). In our grafts of early-migrating mesencephalic neural crest, we note a substantial quail cell contribution to the entire lower jaw skeleton including the quadrate, Meckel's cartilage and surrounding membrane bones, to the basihyoid cartilage in the tongue, and to the membrane bones of the upper jaw (not shown). Quail cells are also found in the pterygoid and palatine bones, in the rostrum of the parasphenoid (not shown) and in the scleral cartilage around the eye (Fig. 2F). All these skeletal elements are derived from the neural crest (Noden, 1978a; Couly et al., 1993). Quail cells are found in the postorbital bone (not shown; this element is still cartilaginous at the stages analysed) which is neural crest-derived according to Noden (1978a), but mesoderm-derived according to Couly et al. (1993); however, we also find quail cells in the sphenoid, which is mesoderm-derived (Noden,
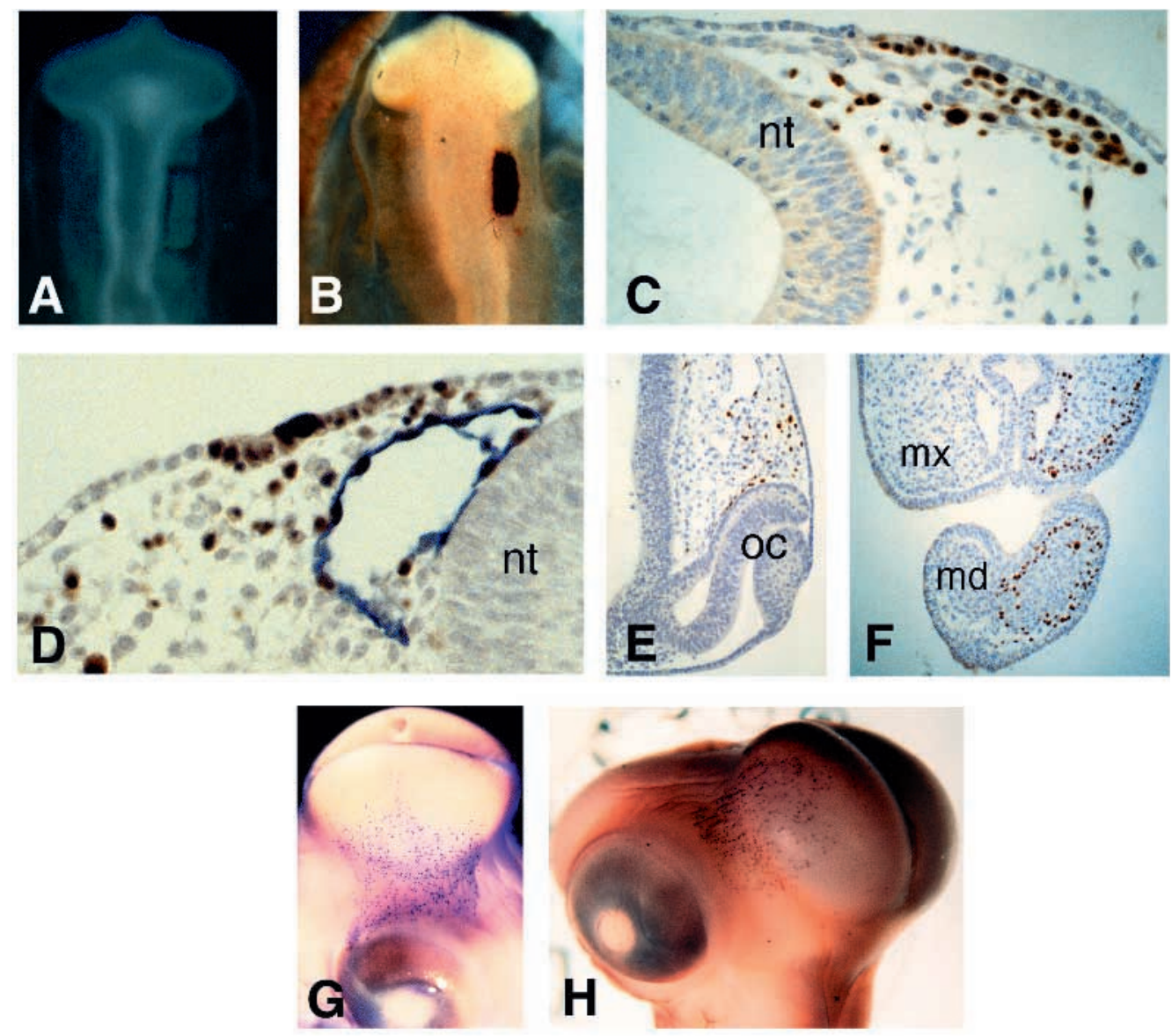

Fig. 1. (A) An 8-somite stage donor quail embryo, in ovo; the graft region has been outlined using a microscalpel. (B) An 8-somite stage chick embryo killed 1 hour post-graft, stained as a whole-mount with QCPN (brown). (C-F) All sections are stained with QCPN for quail cells (brown nuclei) and counterstained with Gill's hematoxylin (blue nuclei). (C) Transverse section, 2 hours post-graft (isochronic graft of early-migrating neural crest). (D) Transverse section, 7 hours post-graft (heterochronic graft of late-migrating neural crest into an 8-somite stage host), double-stained with QCPN (brown nuclei) and QH1 (quail endothelial cell-specific antibody; blue cytoplasm). (E) Oblique frontal section, 24 hours post-graft (isochronic graft of early-migrating neural crest): quail cells are associated with and dorsal to the optic cup (oc). Dorsal is up. (F) Oblique transverse section, 24 hours post-graft (isochronic graft of early-migrating neural crest): quail neural crest cells surround the somitic mesenchymal core of both the maxillary process $(\mathrm{mx})$ and the mandibular arch (md). Dorsal is up. $(\mathrm{G}, \mathrm{H})$ Whole-mount QCPN-stained embryos (4 days post-graft): the quail ectoderm remains dorsal, whether the graft is performed early (8-somite stage; $\mathrm{G}$ ) or late (12-somite stage; $\mathrm{H})$. nt, neural tube; oc, optic cup; mx, maxillary process; md, mandibular arch. 

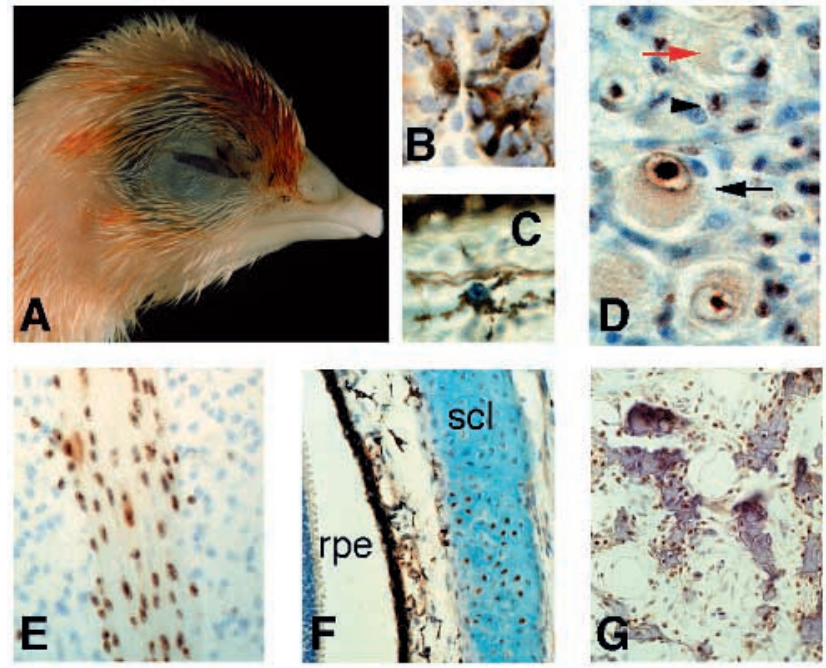

Fig. 2. Quail cells from isochronic grafts of early-migrating (8somite stage) mesencephalic neural crest form melanocytes (A-C), neurons and glia $(\mathrm{D}, \mathrm{E})$ and skeletal derivatives $(\mathrm{F}, \mathrm{G})$ in host chick embryos. All sections are stained with QCPN to show quail cells (brown nuclei; blue nucleus in $\mathrm{C}$ ) and counterstained with Gill's hematoxylin (blue nuclei). (A) The head of a 14.5 day-old embryo showing brown and black quail pigment in the feathers on the operated side. (B) Quail melanocytes (brown nuclei) in the ectoderm of a hair follicle in a 10.5 day-old embryo. (C) Quail melanocyte (blue nucleus) in the choroid layer of the eye of a 10.5 day-old embryo. (D) Quail cells form both large ciliary neurons (black arrow) and small choroid neurons (black arrowhead) in the ciliary ganglion of a 13.5 day-old embryo; red arrow indicates a chick ciliary neuron. (E) Quail Schwann cells along the oculomotor nerve of a 5.5 day-old embryo. (F) Quail cells in differentiated scleral cartilage (scl; stained with Alcian blue) in a 10.5 day-old embryo. (G) Quail cells in membrane bone in the upper jaw of the same 10.5 day-old embryo. rpe, retinal pigment epithelium; scl, scleral cartilage.

1978a; Couly et al., 1993), suggesting minor mesodermal contamination of the graft. Quail dermis and feather pulp are found both in the jaws and in more dorsal regions (all dermis in the head is formed by the neural crest; Couly et al., 1993).

In summary, the early-migrating mesencephalic neural crest cell population is not lineage-restricted, as it forms melanocytes, neurons, glia and skeletal derivatives during normal development. It contributes to both dorsal (e.g. melanocytes, ciliary ganglion) and ventral derivatives (e.g. skeletal components of the jaws).

\section{Neuronal clusters in the ciliary ganglion are not clonal}

The parasympathetic ciliary ganglion, situated near the optic nerve (rostral to the ophthalmic nerve, along the lateral aspect of the oculomotor nerve), is derived from the neural crest (Hammond and Yntema, 1958; Narayanan and Narayanan, 1978a; Noden, 1978b). It contains two populations of cholinergic neurons: large ciliary neurons, which synapse onto the ciliary body and the striated muscle of the iris, and small choroid neurons, which synapse onto the smooth muscle of the vasculature of the choroid layer. Quail cells in our chimeric embryos make a substantial contribution to both cell types (Fig. 2D). At late stages, each large ciliary neuron is surrounded by many small choroid neurons to form a cluster (Fig. 2D). Our results show clearly that these clusters are not clonal, since a single ciliary neuron, whether quail or chick, is surrounded by a mixture of quail and chick choroid neurons (Fig. 2D). Since no wholly quail or wholly chick neuronal clusters are seen, the clusters cannot originate from a single cell.

\section{Late-migrating mesencephalic neural crest cells only contribute to dorsal derivatives during normal development}

After performing isotopic grafts of the late-migrating (12- to 13-somite stage) mesencephalic neural crest, we analysed 10 chimeric embryos killed from 1.5 to $10 \mathrm{dpg}$ (i.e. ranging in age from E3 to E11.5; Table 1). During normal development, lateemigrating mesencephalic neural crest cells give rise to melanocytes (Fig. 3A), parasympathetic neurons in the ciliary ganglion (Fig. 3B), and Schwann cells along the oculomotor and trigeminal nerves (Fig. 3C) and along nerves in the frontonasal mass (not shown). They contribute to the frontal bone (Fig. 3E), to dorsal dermis (not shown), and, to a very minor extent, to the scleral cartilage of the eye (Fig. 3D). They are never found in the jaws (Fig. 6F) except as Schwann cells (not shown), which presumably migrate there along trigeminal nerve fibres. Thus these cells do not participate in any ventral structures.

In summary, the late-migrating mesencephalic neural crest cell population is not lineage-restricted, as it forms melanocytes, neurons, glia and skeletal derivatives during normal development. However, it makes much less cartilage and bone than the early-migrating population, and its derivatives are restricted dorsally.

\section{Mesencephalic neural crest cells do not normally form neurons in the trigeminal ganglion, but do so when grafted adjacent to $\mathrm{r} 1,2$}

In all chimeras receiving a graft of early- or late-migrating
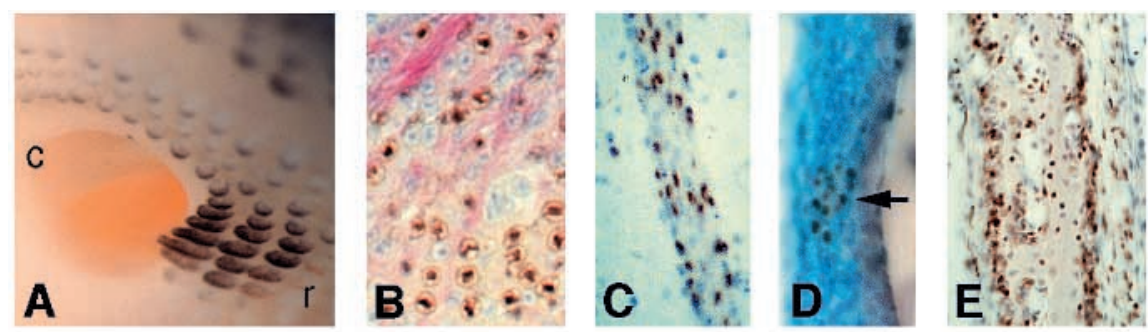

Fig. 3. Quail cells from isochronic grafts of late-migrating (12-somite stage) mesencephalic neural crest cells form melanocytes (A), neurons and glia (B,C), and dorsal skeletal derivatives $(\mathrm{D}, \mathrm{E})$ in host chick embryos. All sections are stained with QCPN to show quail cells (brown nuclei) and counterstained with Gill's hematoxylin (blue nuclei). (A) Quail-pigmented (brown) feather buds around the ear on the operated side of an 11.5 day-old embryo (r, rostral; c, caudal). (B) Quail neurons in the ciliary ganglion of a 5.5 day-old embryo; pink indicates neurofilament antibody staining. (C) Quail Schwann cells along the oculomotor nerve of a 5.5 day-old embryo. (D) Quail cells (arrow) in scleral cartilage (Alcian blue-stained) of an 11.5 day-old embryo. (E) Quail cells in the frontal bone of the same 11.5 day-old embryo. r, rostral; c, caudal. 
mesencephalic neural crest cells (plus overlying ectoderm), large quail neurons are found in the distal ophthalmic lobe of the trigeminal ganglion (opV; Fig. 4A,B) and along the ophthalmic trigeminal nerve of host embryos (Fig. 4C). Three chimeric embryos were analysed 4 days after receiving an isotopic graft of the ectoderm adjacent to the mesencephalon at the 5- or 6-somite stage (when no neural crest cells are included in the graft): the same large quail neurons are seen (Fig. 4D,E). This confirmed that the large neurons are derived from the ectodermal component of the graft, which includes part of the ophthalmic trigeminal placode (D'Amico-Martel and Noden, 1983).

A few non-neuronal quail cells are scattered in the trigeminal ganglion after isotopic grafts of early- or late-migrating mesencephalic neural crest cells; these probably represent neural crest-derived satellite cells (Fig. 4B). The mesencephalic neural crest does not seem to be a major source of trigeminal ganglion neurons in our grafts, whether early or late, since no or very few quail neurons are seen in the proximal region of the ganglion (Fig. 4A,F) where neural crest-derived neurons are located (Hamburger, 1961). In fact, the metencephalic region (hereafter referred to as $\mathrm{r} 1,2$ for presumptive rhombomeres 1 and 2) is the major source of neural crest cell-derived trigeminal ganglion neurons (Noden, 1975), and we find quail neurons in the proximal trigeminal ganglion after isotopically grafting neural crest cells adjacent to the $r 1,2$ region at the 12-somite stage (two embryos at 4 dpg; Fig. 4G).

At the 8-somite stage, neural crest cell emigration from r1,2 has barely begun; neural crest cells are only seen adjacent to the most rostral part of $\mathrm{r} 1,2$. In order to test whether the earlymigrating mesencephalic crest can form trigeminal neurons, we heterotopically grafted early-migrating mesencephalic neural crest cells adjacent to the $\mathrm{r} 1,2$ region in two 8-somite stage embryos. In both embryos, quail neurons are found in the proximal region of the ganglion at 4 dpg (Fig. $4 \mathrm{H}$ ). Thus, the early-migrating mesencephalic neural crest can form trigeminal ganglion neurons. trigeminal ganglion.

\section{Early- and late-migrating mesencephalic neural crest cells form clusters at specific cranial nerve exit points}

In all embryos receiving isotopic grafts of either early- or latemigrating mesencephalic neural crest cells, there is substantial clustering of quail cells (presumably Schwann cells; see Nierderländer and Lumsden, 1996) at the exit point of the oculomotor nerve in the ventral mesencephalon (Fig. 5A,C), but not at the exit point of the trigeminal nerve in $\mathrm{r} 2$ (Fig. 5B,D). Conversely, after isotopic grafts of the neural crest adjacent to $\mathrm{r} 1,2$ at the 12 -somite stage (two embryos at $4 \mathrm{dpg}$ ), no or very few quail Schwann cells are seen along the oculomotor nerve, and none at its exit point (Fig. 5E) while many cells are clustered at the trigeminal exit point (Fig. 5F). When the earlymigrating mesencephalic neural crest is heterotopically grafted adjacent to r1,2 (two embryos at $4 \mathrm{dpg}$ ), quail Schwann cells along the oculomotor nerve are confined to distal regions of the nerve (not shown), and no or very few quail cells are found
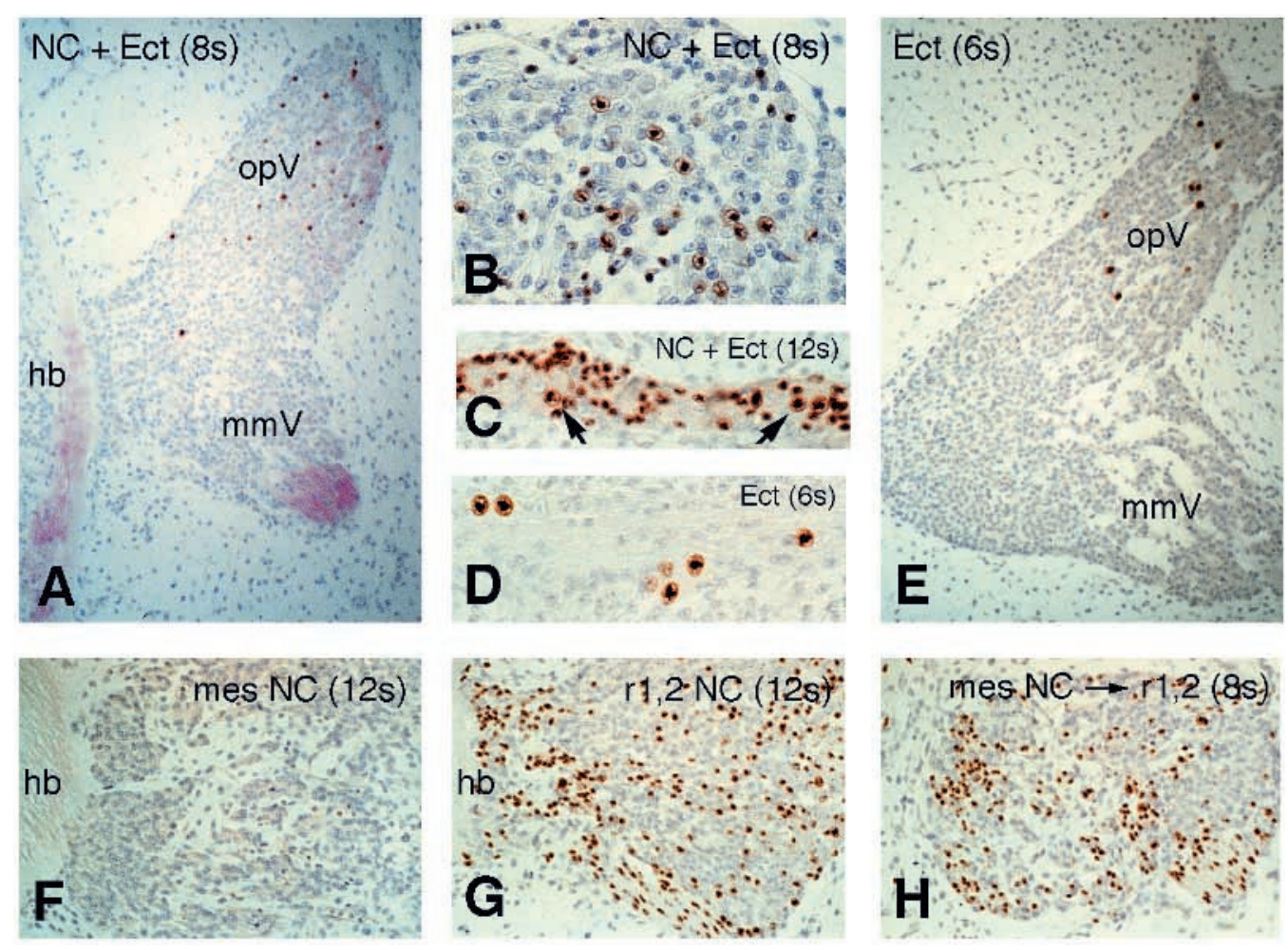

Fig. 4. Parasagittal sections through 5.5 day-old embryos showing quail placode (A-E) and neural crest (F$\mathrm{H})$ contributions to the trigeminal ganglion after isotopic and heterotopic grafts of migrating mesencephalic and metencephalic ( 11,2$)$ neural crest (NC) plus overlying ectoderm (Ect). All sections are stained with QCPN to show quail cells (brown nuclei) and counterstained with Gill's hematoxylin (blue nuclei). (A) Large quail neurons in the ophthalmic lobe of the trigeminal ganglion (opV) after an isotopic graft of early-migrating (8-somite stage) mesencephalic NC + Ect. (B) Higher power view of opV in a different embryo after the same type of graft as in A. (C) Large quail neurons and quail Schwann cells along the ophthalmic trigeminal nerve after an isotopic graft of late-migrating (12-somite stage) mesencephalic NC + Ect. (D) Large quail neurons along the ophthalmic trigeminal nerve after an isotopic graft of ectoderm at the 5-6-somite stage. (E) Large quail neurons in opV after the same type of graft as in D. (F) The proximal region of the trigeminal ganglion (proximal V) lacks quail cells after an isotopic graft of late-migrating mesencephalic NC. (G) Quail cells in proximal V after an isotopic graft of migrating 12somite stage $\mathrm{r} 1,2$ neural crest. (H) Quail cells in proximal V after a heterotopic graft of early-migrating mesencephalic neural crest to r1,2 at the 8-somite stage. Ect, ectoderm; hb, hindbrain; mes, mesencephalic; $\mathrm{mmV}$, maxillo-mandibular lobe of the trigeminal ganglion; $\mathrm{NC}$, neural crest; opV, ophthalmic lobe of the 
at the oculomotor exit point (Fig. 5F), while quail cells cluster around the trigeminal nerve exit point (Fig. 5G). Quail Schwann cells are also sometimes found along cranial nerves IV (trochlear) and VI (abducens), but are not seen clustered at their exit points (respectively located dorsally near the isthmus, and ventrally in the myelencephalon). Thus, in heterotopic grafts, neural crest cells cluster at the cranial nerve exit point in the region through which they are migrating, rather than being attracted to the nerve exit point specific to their region of origin.

\section{Heterochronic grafts behave in accordance with their new environment}

When the late-migrating (12-somite stage) mesencephalic neural crest cell population is substituted for the earlymigrating (8-somite stage) population (three embryos at 4-5 dpg) the graft makes a substantial contribution to the lower jaw skeleton (Fig. 6B-D) and quail cells differentiate into cartilage in Meckel's cartilage in the lower jaw (Fig. 6D). Although the embryos were all killed before ossification began, many quail cells are found in the mesenchyme associated with Meckel's cartilage (Fig. 6C), suggesting that the grafted cells will eventually contribute to the membrane bones in the lower jaw. Quail cells also contribute to the scleral cartilage around the eye (Fig. $6 \mathrm{E})$, but are not seen in large numbers in the upper jaw or in more dorsal skull elements, perhaps owing to the smaller number of cells in grafts of late-migrating neural crest. Quail neurons are found in the ciliary ganglion; quail Schwann cells are seen along the oculomotor and trigeminal nerves and along nerves in the frontonasal mass (not shown). We did not look for pigment formation as both early- and late-migrating mesencephalic neural crest cells form melanocytes during normal development. The graft thus behaves like a graft of earlymigrating neural crest (Figs 2 and 6A).

Conversely, when the early-migrating mesencephalic neural crest cell population is substituted for the late-migrating population (three embryos at $4 \mathrm{dpg}$ ), it makes no contribution to the jaw skeleton (Fig. 6G), although it does contribute to the scleral cartilage around the eye (Fig. $6 \mathrm{H}$ ). Quail neurons are seen in the ciliary ganglion and quail Schwann cells are found along the oculomotor and trigeminal nerves and along nerves in the frontonasal mass (not shown). The graft thus behaves like a graft of late-migrating neural crest (Figs 3 and 6F).

\section{Late-migrating neural crest cells are excluded from ventral structures by earlier-migrating cells}

We wished to test whether the dorsal restriction of latemigrating neural crest cells is due to the presence of earliermigrating neural crest cells in ventral structures, or to a temporal change in the environment other than that provided by neural crest cells. We unilaterally ablated the neural fold (and any already-migrating neural crest) of ten chick embryos at stages ranging from 6-9 somites, allowed the embryos to grow to the 12-somite stage, and isotopically grafted latemigrating (12-somite stage) quail neural crest into either the crest-ablated side alone (4 embryos) or into both sides $(6$

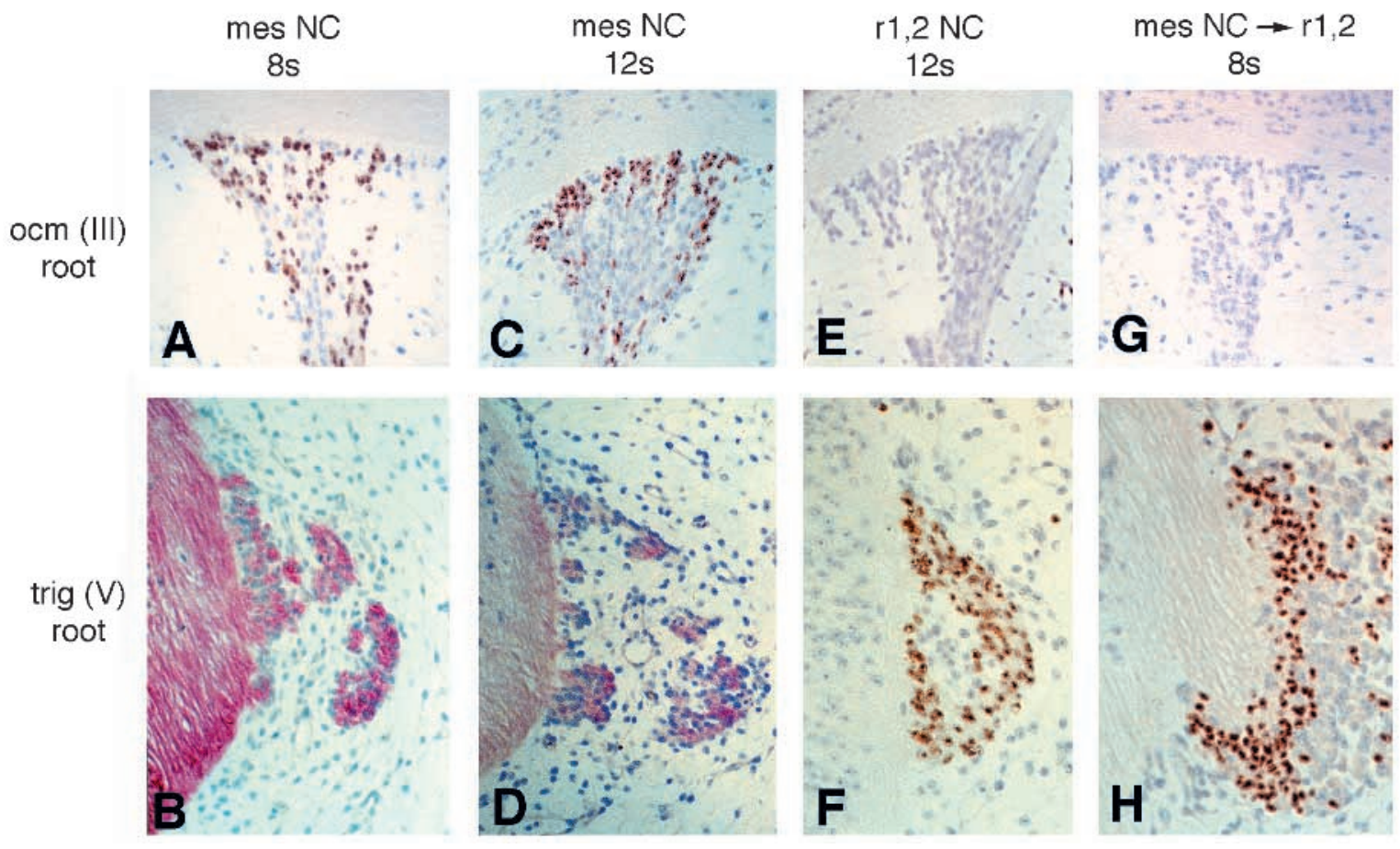

Fig. 5. Quail neural crest cells cluster at cranial nerve exit points specific to the axial level at which they migrate. All images are parasagittal sections through 5.5 day-old embryos, stained with QCPN to show quail cells (brown nuclei) and counterstained with Gill's hematoxylin (blue nuclei). (A-D) After isotopic grafts of early- or late-migrating mesencephalic neural crest (mes NC), quail cells cluster at the oculomotor (ocm) nerve exit point in the ventral mesencephalon $(A, C)$ but not at the trigeminal (trig) nerve exit point in $\mathrm{r} 2$ (B,D). (E-H) After isotopic grafts of r1,2 neural crest at the 12-somite stage (E,F), or after heterotopic grafts of early-migrating mesencephalic neural crest to r1,2 (G,H), quail cells cluster at the trigeminal nerve exit point $(\mathrm{F}, \mathrm{H})$ but not at the oculomotor nerve exit point $(\mathrm{E}, \mathrm{G})$. mes, mesencephalic; $\mathrm{NC}$, neural crest; ocm, oculomotor nerve (cranial nerve III); trig, trigeminal nerve (cranial nerve V). 
embryos) of the hosts. Analysis 16 hours to 2 days later showed that on the crest-ablated side, quail neural crest cells are found in the mandibular arch (Fig. 6I-K). In our previously described grafts of late-migrating neural crest (see last section), quail cells are never found in the mandibular arch, nor are they found there on the control side of those crest-ablated embryos that received a bilateral graft (Fig. 6I). Hence the latemigrating neural crest is normally excluded from ventral structures (such as the jaws) by neural crest cells that had migrated earlier.

\section{DISCUSSION}

We have used quail-chick chimeras to label specifically early- or late-migrating neural crest cell populations in the mesencephalic region. The early-migrating population is that which is adjacent to the mesencephalon at the 8-somite stage; the late-migrating population is that adjacent to the mesencephalon at the 12-somite stage. We show that neither the early-migrating nor the late-migrating populations are lineagerestricted, both forming melanocytes, neurons, glia, cartilage and bone during normal development. Our analysis is at the population level only and cannot be taken as evidence for lack of lineage restriction of individual cells. Our results also demonstrate that the early-migrating neural crest does not occupy its target sites in any obvious order, but distributes along the entire dorsoventral axis. The late-migrating population, in contrast, forms much less cartilage and bone than the early-migrating population, and its derivatives are restricted dorsally during normal development. When the late-migrating population is substituted for the early-migrating population, it makes a substantial contribution to both cartilage and bone in the lower jaw skeleton. Similarly, when the late-migrating population is grafted into a late (12-somite stage) host whose crest had previously been ablated, it migrates ventrally into the jaws. This shows that the dorsal restriction of late-migrating cells during normal development is due to their exclusion from ventral structures by neural crest cells that had migrated earlier, rather than to a temporal change in the environment or to any intrinsic difference in migratory ability between early- and late-migrating populations. Thus the changes in neural crest cell fate with time, at least in the head of the avian embryo, are primarily related to the different environments encountered by neural crest cells emigrating at different times.

\section{Neural crest cell plasticity}

Certain fates are normally unavailable to neural crest cells leaving the neural tube at a particular time. In the trunk, early-migrating trunk neural
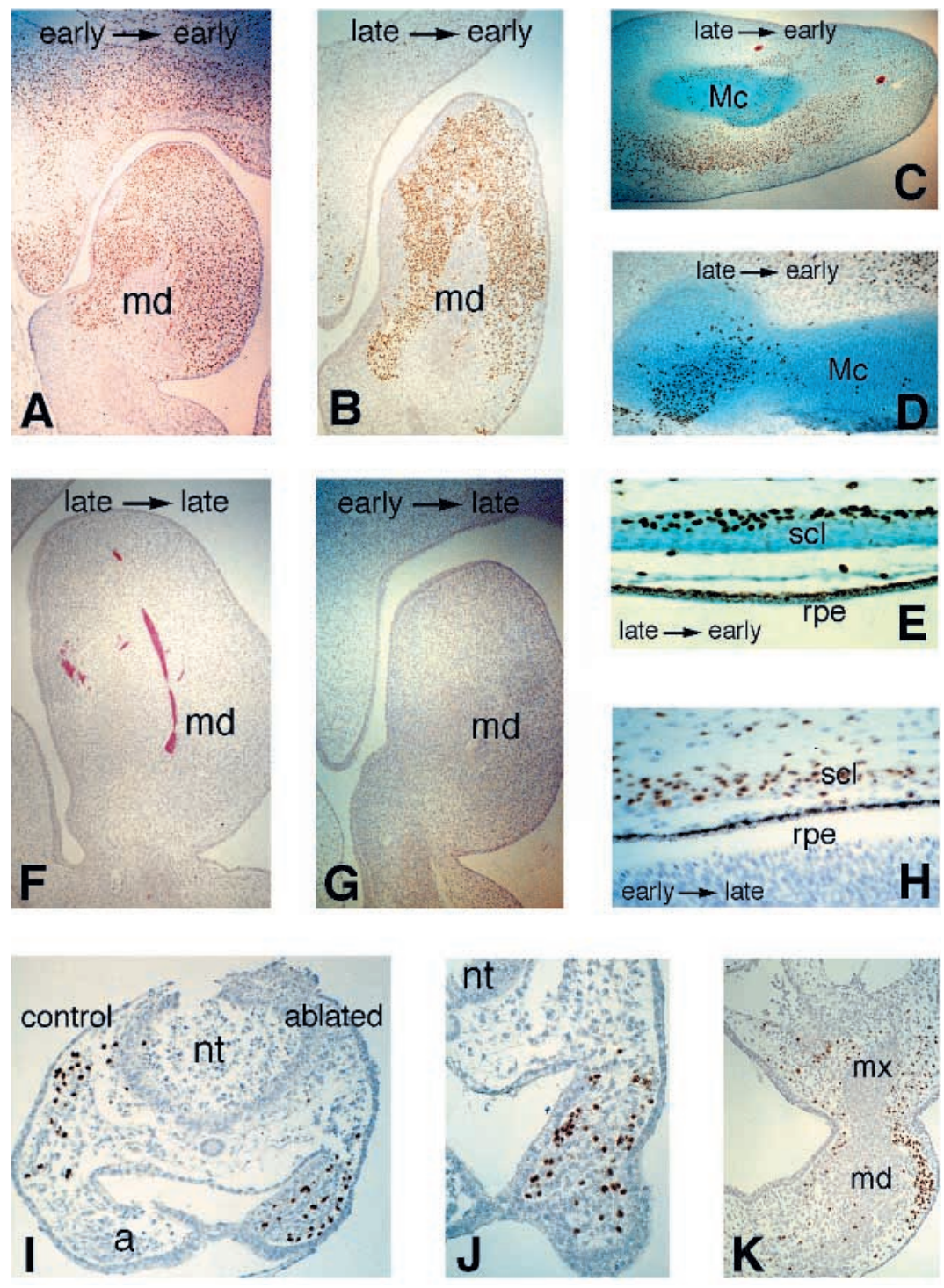

Fig. 6. Heterochronic grafts of migrating mesencephalic neural crest (NC) behave like isochronic grafts of host-stage NC. All sections are parasagittal and stained with QCPN to show quail cells (brown nuclei) and counterstained with Gill's hematoxylin (blue nuclei). (A,B) 5.5 day-old embryos with quail cells in the jaws after (A) an isochronic graft of early-migrating (8-somite stage) $\mathrm{NC}$ or (B) a heterochronic graft of late-migrating (12-somite stage) $\mathrm{NC}$ at the 8 -somite stage. (C-E) Alcian blue-stained sections of a 6.5 day-old embryo after a heterochronic graft of late-migrating $\mathrm{NC}$ at the 8-somite stage, showing (C,D) quail cells in Meckel's cartilage (Mc) and surrounding mesenchyme (presumptive membrane bone) in the lower jaw, and (E) in scleral cartilage (scl). rpe, retinal pigment epithelium. (F,G) No quail cells are in the jaws of 5.5 day-old embryos after (F) an isochronic graft of late-migrating $\mathrm{NC}$ or $(\mathrm{G})$ a heterochronic graft of earlymigrating $\mathrm{NC}$ at the 12-somite stage. $(\mathrm{H})$ Quail cells in presumptive scleral cartilage in the same embryo as in G. (I-K) Late-migrating mesencephalic NC cells migrate into the jaws when grafted into a 12-somite stage, neural crestablated host. (I) Transverse section, 2 day-old embryo: quail cells are dorsal on the unoperated side, but present in branchial arch 1 (a) on the crest-ablated side. Quail cells associated with the neural tube on the left side are probably endothelial cells. (J) Quail cells in branchial arch 1 on the crest-ablated side of a 2.5 day-old embryo. (K) Quail cells in the maxillary process $(\mathrm{mx})$ and mandibular arch (md) on the crest-ablated side of a 3.5 day-old embryo. a, branchial arch 1; Mc, Meckel's cartilage; md, mandibular arch; mx, maxillary process; nt, neural tube; rpe, retinal pigment epithelium; scl, scleral cartilage. 
crest cells are excluded from the dorsolateral pathway beneath the ectoderm, at least in part (see Erickson and Goins, 1995) because of the presence of migration-inhibiting glycoconjugates which later disappear (Oakley et al., 1994). Here, we have shown that ventral fates (such as the jaw skeleton) are normally unavailable to late-migrating neural crest cells in the head because earlier-migrating neural crest cells exclude them from ventral regions; however, these fates are readily adopted by late-migrating neural crest cells when they are substituted for the early-migrating population or when all earlier-migrating cells are ablated. This highlights the plasticity of migrating neural crest cells. Similarly, in the trunk, heterochronic grafts of pre-migratory neural crest have shown that late-migrating trunk neural crest cells, which normally form only dorsal derivatives, populate both dorsal and ventral derivatives when placed in an 'early' environment (Weston and Butler, 1966). These results complement the many heterotopic grafting experiments showing that pre-migratory neural crest cells, originating from one axial level, can give rise to a completely different set of derivatives appropriate for their new position (e.g. Le Douarin and Teillet, 1974; reviewed by Le Douarin, 1982).

There is some limited evidence for qualitative differences between early- and late-migrating trunk neural crest cells in the chick. Early-migrating trunk neural crest cells placed in a 'late' environment do not follow the dorsolateral pathway taken by late-migrating neural crest cells (Erickson and Goins, 1995). Late-migrating trunk neural crest cells placed in an 'early' environment, despite migrating ventrally to colonise the sympathetic ganglia, do not form the adrenergic cells appropriate to this location (Artinger and Bronner-Fraser, 1992). In the zebrafish, early- and late-migrating trunk neural crest cells can be distinguished prior to migration by their position within the neural tube (Raible et al., 1992). Early-migrating cells form neurons (amongst other derivatives). Late-migrating cells do not form neurons, either during normal development or when transplanted into an 'early' environment, as if they lack neurogenic potential (Raible and Eisen, 1996). However, these authors went on to show that late-migrating cells can form neurons if the early-migrating cells are ablated, whether before or during migration. Hence early-migrating zebrafish neural crest cells inhibit late-migrating cells from forming neurons. In our heterochronic experiments, the native population is entirely replaced by the grafted population, so that this kind of fate regulation (if it exists in the chick) could not operate. Indeed, our heterochronically grafted cells behave entirely according to their new environment (just as do heterotopically grafted premigratory neural crest cells, in which donor neural folds are substituted for host neural folds).

\section{Both early- and late-migrating cranial neural crest cells form melanocytes during normal development}

We have shown that both early- and late-migrating mesencephalic neural crest cells form melanocytes during normal development. With regard to the axial origin of melanocytes, we note that since Niu's (1947) finding that the trunk neural crest contributes largely to the pigmentation of the head in urodele amphibia, it has sometimes been wrongly assumed that the cranial neural crest in all vertebrates gives rise to very few pigment cells and that the head is largely pigmented by trunk neural crest. Melanin has even been used as a 'trunk-specific' phenotypic marker for avian neural crest cells in vitro (Darland and Leblanc, 1996). The cranial neural crest of birds may have a lower capacity for melanogenesis than the trunk neural crest (Smith et al., 1977), but it nonetheless achieves the pigmentation of the head, as shown by Teillet (1971).

With regard to the time of origin of melanocytes, it appears that in the avian trunk, only late-migrating neural crest cells follow the dorsolateral migration pathway beneath the ectoderm and form melanocytes (Serbedzija et al., 1989; Erickson et al., 1992; Kitamura et al., 1992). We have shown that avian mesencephalic neural crest cells, which exclusively follow a sub-ectodermal migration pathway (Tosney, 1982), are melanogenic throughout their development. In the chick vagal region (Thiery et al., 1982) and in the trunk of the mouse and the axolotl (Serbedzija et al., 1990; Löfberg et al., 1980), the subectodermal pathway is colonised by early-migrating neural crest cells, which presumably form melanocytes. Earlymigrating zebrafish neural crest cells, which follow a ventral migration pathway between the neural tube and somite, form melanocytes as well as neurons and glia (Raible and Eisen, 1994). Considering all these lines of evidence, it seems highly unlikely that early-migrating avian trunk neural crest cells should lack melanogenic potential. Rather, these cells probably fail to encounter melanogenic specification signals associated with the subectodermal migration pathway (Perris et al., 1988), from which they are excluded (Erickson and Goins, 1995).

\section{Neural crest cell clustering at cranial nerve exit points}

The clustering of early- and late-migrating mesencephalic neural crest cells that we see at the exit point of the oculomotor nerve may reflect the specific migration of a subpopulation of neural crest cells to branchiomotor nerve exit points (Nakagawa and Takeichi, 1995; Niederländer and Lumsden, 1996). These neural crest cells, which express cadherin-7, are hypothesised to secrete molecules to guide outgrowing branchiomotor neurons. Niederländer and Lumsden (1996) used quail-chick grafts of premigratory neural crest to show that late-emigrating, cadherin-7-expressing neural crest cells from r2-4 cluster at the trigeminal (r2) and facial (r4) exit points, while neural crest cells from r4-6 migrate to the facial, glossopharyngeal (r6) and vagal (r7) nerve exit points. Our results extend these observations to the early-migrating neural crest cell population. As with our finding that mesencephalic neural crest cells grafted by $\mathrm{r} 1,2$ cluster at the trigeminal exit point in r2 rather than at the oculomotor exit point in the mesencephalon, Niederländer and Lumsden (1996) found that neural crest cells from other axial levels migrate to the branchiomotor exit point appropriate for the axial level of the graft. Nakagawa and Takeichi (1995) noted that cadherin-7 is expressed at the oculomotor exit point as well as at more caudal exit points, suggesting that the neural crest cells seen here in our grafts may also express cadherin-7. The function of cadherin-7 in these cells is unknown.

\section{Conclusions}

We have shown that early- and late-migrating mesencephalic neural crest populations are not lineage-restricted in the avian embryo in vivo. Their normal fates differ in that the latemigrating population is restricted to dorsal derivatives, and forms much less cartilage and bone than the early-migrating population. However, our heterochronic transplants show that 
each population can behave like the other when placed in the appropriate environment, suggesting that there is no intrinsic difference between them in either potential or migratory ability. When the late-migrating population is grafted into a crestablated, late-stage host, it migrates ventrally into the jaws. Hence the dorsal fate restriction of the late-migrating population relates to the presence of earlier-migrating crest and not to any temporal change in the environment. These results emphasise both the plasticity of neural crest cell populations and the importance of the environment in determining neural crest cell fate.

Thanks to Delphine Champeval and Claude Oudin for technical assistance, and to Yann Rantier for photographs of embryos. Thanks to Michael Rodrigues for suggesting the early ablation, late grafting experiment, and to Andy Groves and Mark Selleck for helpful comments on the manuscript. This work was supported by Wellcome Trust Travelling Research Fellowship 043093/Z/94/Z, and by Human Frontier Science Program Fellowship LT-63/96.

\section{REFERENCES}

Artinger, K. B. and Bronner-Fraser, M. (1992). Partial restriction in the developmental potential of late emigrating avian neural crest cells. Dev. Biol. 149, 149-157.

Baroffio, A., Dupin, E. and Le Douarin, N. M. (1988). Clone-forming ability and differentiation potential of migratory neural crest cells. Proc. Natl. Acad. Sci. USA 85, 5325-5329.

Baroffio, A., Dupin, E. and Le Douarin, N. M. (1991). Common precursors for neural and mesectodermal derivatives in the cephalic neural crest. Development 112, 301-305.

Bronner-Fraser, M. and Fraser, S. E. (1988). Cell lineage analysis reveals multipotency of some avian neural crest cells. Nature 335, 161-164.

Bronner-Fraser, M. and Fraser, S. (1989). Developmental potential of avian trunk neural crest cells in situ. Neuron 3, 755-766.

Couly, G. and Le Douarin, N. M. (1990). Head morphogenesis in embryonic avian chimeras: evidence for a segmental pattern in the ectoderm corresponding to the neuromeres. Development 108, 543-558.

Couly, G. F., Coltey, P. M. and Le Douarin, N. M. (1992). The developmental fate of the cephalic mesoderm in quail-chick chimeras. Development 114, 115.

Couly, G. F., Coltey, P. M. and Le Douarin, N. M. (1993). The triple origin of the skull in higher vertebrates: a study in quail-chick chimeras. Development 117, 409-429.

D'Amico-Martel, A. and Noden, D. M. (1983). Contributions of placodal and neural crest cells to avian cranial peripheral ganglia. Am. J. Anat. 166, 445468.

Darland, T. and Leblanc, G. G. (1996). Immortalised Hensen's node cells secrete a factor that regulates avian neural crest cell fates in vitro. Dev. Biol. 176, 62-75.

Erickson, C. A., Duong, T. D. and Tosney, K. W. (1992). Descriptive and experimental analysis of the dispersion of neural crest cells along the dorsolateral path and their entry into ectoderm in the chick embryo. Dev. Biol. 151, 251-272.

Erickson, C. A. and Goins, T. L. (1995). Avian neural crest cells can migrate in the dorsolateral path only if they are specified as melanocytes. Development 121, 915-924.

Fraser, S. E. and Bronner-Fraser, M. (1991). Migrating neural crest cells in the trunk of the avian embryo are multipotent. Development 112, 913-920.

Hamburger, V. (1961). Experimental analysis of the dual origin of the trigeminal ganglion in the chick embryo. J. Exp. Zool. 148, 91-117.

Hammond, W. S. and Yntema, C. L. (1958). Origin of ciliary ganglia in the chick. J. comp. Neur. 110, 367-390.

Johnston, M. C. (1966). A radioautographic study of the migration and fate of cranial neural crest cells in the chick embryo. Anat. Rec. 156, 143-156.

Kitamura, K., Takiguchi-Hayashi, K., Sezaki, M., Yamamoto, H. and Takeuchi, T. (1992). Avian neural crest cells express a melanogenic trait during early migration from the neural tube: observations with the new monoclonal antibody, 'MEBL-1'. Development 114, 367-378.
Le Douarin, N. (1982). The Neural Crest. Cambridge University Press, Cambridge.

Le Douarin, N. M. and Teillet, M. A. (1974). Experimental analysis of the migration and differentiation of neuroblasts of the autonomic nervous system and of neuroectodermal mesenchymal derivatives, using a biological cell marking technique. Dev. Biol. 41, 162-184.

Le Lièvre, C. (1974). Rôle des cellules mésectodermiques issues des crêtes neurales céphaliques dans la formation des arcs branchiaux et du squelette viscéral. J. Embryol. Exp. Morphol. 31, 453-477.

Le Lièvre, C. S. (1978). Participation of neural crest-derived cells in the genesis of the skull in birds. J. Embryol. Exp. Morphol. 47, 17-37.

Le Lièvre, C. and Le Douarin, N. M. (1975). Mesenchymal derivatives of the neural crest: analysis of chimaeric quail and chick embryos. J. Embryol. Exp. Morphol. 34, 125-154.

Löfberg, J., Ahlfors, K. and Fällstrom, C. (1980). Neural crest cell migration in relation to extracellular matrix organization in the embryonic axolotl trunk. Dev. Biol. 75, 148-167.

Lumsden, A., Sprawson, N. and Graham, A. (1991). Segmental origin and migration of neural crest cells in the hindbrain region of the chick embryo. Development 113, 1281-1291.

Nakagawa, S. and Takeichi, M. (1995). Neural crest cell-cell adhesion controlled by sequential and subpopulation-specific expression of novel cadherins. Development 121, 1321-1332.

Narayanan, C. H. and Narayanan, Y. (1978a). Determination of the embryonic origin of the mesencephalic nucleus of the trigeminal nerve in birds. J. Embryol. Exp. Morph. 43, 85-105.

Narayanan, C. H. and Narayanan, Y. (1978b). On the origin of the ciliary ganglion in birds studied by the method of interspecific transplantation of embryonic brain regions between quail and chick. J. Embryol. Exp. Morph. 47, 137-148.

Nichols, D. H. (1986). Formation and distribution of neural crest mesenchyme to the first pharyngeal arch region of the mouse embryo. Am. J. Anat. 176, 221-231.

Niederländer, C. and Lumsden, A. (1996). Late emigrating neural crest cells migrate specifically to the exit points of cranial branchiomotor nerves. Development 122, 2367-2374.

Niu, M. C. (1947). The axial organization of the neural crest, studied with particular reference to its pigmentary component. J. Exp. Zool. 105, 79-113.

Noden, D. M. (1975). An analysis of the migratory behaviour of avian cephalic neural crest cells. Dev. Biol. 42, 106-130.

Noden, D. M. (1978a). The control of avian cephalic neural crest cytodifferentiation. I. Skeletal and connective tissues. Dev. Biol. 67, 296-312.

Noden, D. M. (1978b). The control of avian cephalic neural crest cytodifferentiation. II. Neural tissues. Dev. Biol. 67, 313-329.

Noden, D. M. (1984). Craniofacial development: new views on old problems. Anat. Rec. 208, 1-13.

Noden, D. M. (1993). Spatial integration among cells forming the cranial peripheral nervous system. J. Neurobiol. 24, 248-261.

Oakley, R. A., Lasky, C. J., Erickson, C. A. and Tosney, K. W. (1994). Glycoconjugates mark a transient barrier to neural crest migration in the chicken embryo. Development 120, 103-114.

Pardanaud, L., Altmann, C., Kitos, P., Dieterlen-Lièvre, F. and Buck, C. A. (1987). Vasculogenesis in the early quail blastodisc as studied with a monoclonal antibody recognizing endothelial cells. Development 100, 339349.

Perris, R., von Boxberg, Y. and Lofberg, J. (1988). Local embryonic matrices determine region-specific phenotypes in neural crest cells. Science 241, 8689.

Raible, D. W. and Eisen, J. S. (1994). Restriction of neural crest cell fate in the trunk of the embryonic zebrafish. Development 120, 495-503.

Raible, D. W. and Eisen, J. S. (1996). Regulative interactions in zebrafish neural crest. Development 122, 501-507.

Raible, D. W., Wood, A., Hodsdon, W., Henion, P. D., Weston, J. A. and Eisen, J. S. (1992). Segregation and early dispersal of neural crest cells in the embryonic zebrafish. Dev. Dyn. 195, 29-42.

Schilling, T. F. and Kimmel, C. B. (1994). Segment and cell type lineage restrictions during pharyngeal arch development in the zebrafish embryo. Development 120, 483-494.

Selleck, M. A. J. and Bronner-Fraser, M. (1996). The genesis of avian neural crest cells: a classic embryonic induction. Proc. Natl. Acad. Sci. USA 93, 9352-9357.

Serbedzija, G. N., Fraser, S. E. and Bronner-Fraser, M. (1989). A vital dye analysis of the timing and pathways of avian trunk neural crest cell migration. Development 106, 809-816. 
Serbedzija, G. N., Fraser, S. E. and Bronner-Fraser, M. (1990). Pathways of trunk neural crest cell migration in the mouse embryo as revealed by vital dye labelling. Development 108, 605-612.

Serbedzija, G. N., Burgan, S., Fraser, S. E. and Bronner-Fraser, M. (1991). Vital dye labelling demonstrates a sacral neural crest contribution to the enteric nervous system of chick and mouse embryos. Development 111, 857 866.

Serbedzija, G. N., Bronner-Fraser, M. and Fraser, S. E. (1992). Vital dye analysis of cranial neural crest cell migration in the mouse embryo. Development 116, 297-307.

Serbedzija, G. N., Bronner-Fraser, M. and Fraser, S. E. (1994) Developmental potential of trunk neural crest cells in the mouse. Development 120, 1709-1718.

Sharma, K., Korade, Z. and Frank, E. (1995). Late-migrating neuroepithelial cells from the spinal cord differentiate into sensory ganglion cells and melanocytes. Neuron 14, 143-152.

Sieber-Blum, M. and Cohen, A. (1980). Clonal analysis of quail neural crest cells: They are pluripotent and differentiate in vitro in the absence of nonneural crest cells. Dev. Biol. 80, 96-106.

Smith, J., Cochard, P. and Le Douarin, N. M. (1977). Development of choline acetyltransferase and cholinesterase activities in enteric ganglia derived from presumptive adrenergic and cholinergic levels of the neural crest. Cell Differ. 6, 199-216.

Smith, J., Fauquet, M., Ziller, C. and Le Douarin, N. M. (1979) Acetylcholine synthesis by mesencephalic neural crest cells in the process of migration in vivo. Nature 282, 853-855.
Stemple, D. L. and Anderson, D. J. (1992). Isolation of a stem cell for neurons and glia from the mammalian neural crest. Cell 71, 973-985.

Teillet, M. A. (1971). Recherches sur le mode de migration et la differenciation des melanoblastes cutanes chez l'embryon d'oiseau. Ann. d'Embryol. et de Morph. 1971, 95-109.

Thiery, J. P., Duband, J. L. and Delouvee, A. (1982). Pathways and mechanisms of avian neural crest cell migration and localization. Dev. Biol. 93, 324-343.

Tosney, K. W. (1978). The early migration of neural crest cells in the trunk region of the avian embryo: an electron microscopic study. Dev. Biol. 62, 317-333.

Tosney, K. W. (1982). The segregation and early migration of cranial neural crest cells in the avian embryo. Dev. Biol. 89, 13-24.

Tucker, G. C., Aoyama, H., Lipinski, M., Turz, T. and Thiery, J. P. (1984)

Identical reactivity of monoclonal antibodies HNK-1 and NC-1: Conservation in vertebrates on cells derived from neural primordium and on some leukocytes. Cell Differ. 14, 223-230.

Weston, J. A. (1963). A radioautographic analysis of the migration and localization of trunk neural crest cells in the chick. Dev. Biol. 6, 279-310.

Weston, J. A. and Butler, S. L. (1966). Temporal factors affecting localization of neural crest cells in the chicken embryo. Dev. Biol. 14, 246-266.

Ziller, C., Dupin, E., Brazeau, P., Paulin, D. and Le Douarin, N. M. (1983). Early segregation of a neuronal precursor cell line in the neural crest as revealed by culture in a chemically defined medium. Cell 32, 627-638.

(Accepted 4 May 1997) 